\title{
PEMIKIRAN KI HAJAR DEWANTARA TERHADAP PENDIDIKAN
}

\author{
SUPARLAN \\ STIT Palapa Nusantara Lombok NTB \\ Maniahparlan66@gmail.com
}

\begin{abstract}
Raden Mas Soewardi Soerjaningrat was his real name but in 1922 became KI Hajar Dewantara, He was born in Yogyakarta on Thursday legi on 2 May 1889 as the 4th son of Prince Suryaningrat, the eldest son of the natures III. Childhood and adolescence is influenced by Javanese literature. Islam and the teachings of ancient Hinduism. The hero he admires from the epic mahabharata is yudistira (the symbol of peace and love) and Sri Krishna (the incarnation of wishnu filled with wisdom).Education is basically a conscious effort to cultivate the potential of human resources of learners by encouraging and facilitating their learning activities, as stated in the law. Facilitate learning activities such as learning aids such as school laboratories, books, classrooms, and others related to the needs of students and teachers in the learning process.

Kata kunci : KI Hajar Dewantara, Pendidikan
\end{abstract}

\section{PENDAHULUAN}

Dalam pengertian dasar, pendidikan adalah proses menjadi, yakni menjadikan seseorang menjadi dirinya sendiri yang tumbuh sejalan dengan bakat, watak, kemapuan, dan hati nuraninya secara utuh. Pendidikan tidak dimaksudkan untuk mencetak karakter dan kemapuan peserta didik sama seperti gurunya, proses pendidikan diarahkan pada proses berfungsinya semua potensi peserta didik secara manusiawi agar mereka menjadi dirinya sendiri yang mempunyai kemampuan dan kepribadian unggul. ${ }^{1}$

Selain itu, dalam pengertian konvensional pengajaran dipandang bersifat mekanistik dan merupakan otonomi guru untuk mengajar, guru menjadi pusat kegiatan. Dengan pendangan seperti ini guru terdorong menyampaikan informasi sebanyak-banyaknya, metode yang dominan yaitu tanya jawab, sekali-kali siswa

\footnotetext{
${ }^{1}$ Dedi Mulyasa, Pendidikan Bermutu,( Bandung PT Remaja Rosdakarya, 2012),HIm. 3.
} 
diberi kesempatan diskusi di bawah pengawasan, bukan bimbingan dan pemeberian motivasi dari guru. Dengan cara ini siswa dianggap telah belajar. ${ }^{2}$

Pendidikan pada dasarnya adalah usaha sadar untuk menumbuhkembangkan potensi sumber daya manusia peserta didik dengan cara mendorong dan memfasilitasi kegiatan belajar mereka, Seperti tercantum dalam undang-undang. ${ }^{3}$ Menfasilitasi kegiatan belajar seperti alat-alat bantu kegiatan belajar seperti laboraturium sekolah, buku, ruangan kelas, dan lain-lain yang terkait dengan kebutuhan siswa dan guru dalam proses pembelajaran.

Pendidikan merupakan sebuah wadah seseorang untuk melakukan perubahan, baik itu perubahan ekonomi, budi pekerti dan lain-lain. Dalam kaitanya dengan kelangsungan dan kemajuan negara, sering sekali pendidikan sebagai pondasi awal untuk melihat apakah negara itu maju atau tidak. Untuk itu pendidikan sebagai hal yang sangant vital dalam membangun suatu negara yang kuat dan bermartabat.

Berbica tetan permasalahan atau problem di dalam dunia pendiidkan di Indoneisa baik melalui media cetak maupun TV. Seperti yang kita saksikan siswa yang saling tawuran antar pelajar sekolah yang satu dengan seklah yang lain, terjadinya pembegalan motor yang sebagianya tersebut di lakukan oleh anak-anak yang masih duduk dibangku sekolah, minum-minuman keras, menggunakan obatobat terlarang, dan semuanya itu sebagian besar di lakukan oleh anak-anak yang masih duduk di bangku sekolah, baik sekolah tingkat pertama (SLTP) atau (SMA).

Jika hal tersebut tidak di tangan secara serius oleh pemerintah, maka Indonesia akan miskin dengan generasi emasnya, sebab para pelaajrayang menjadi benih kemajuan sudah hancur, disebabkan oleh perbuatan-perbuatan yang tidak baik.

Melihat dari permasalahan-permasalahan yang terjadi di dunia pendidikan, maka pemeritah melakukan penanganan atau mencarikan solusi terbaik bagaimana caranya supaya pendidikan di indoneisa ini menjadi baik, mulai dari gaji guru, prasarana di perbaiki, bukan itu juga, pemerintah menaikkan anggaran pedidikan. pemerintah juga mengkaji dan melakukan berbagai penelitian baik itu penelitian

2 Suyono dan Hariyanto, Belajar dan Pembelajaran, (Bandung: PT Remaja Rosdakarya offset, 2012) hlm 16.

${ }^{3}$ Muhibbbin Syah, Psikologi Pendidikan. (Jakarta : PT. Rajagrapindo Persada. 2009). HIm.1 
dari buku dan mengkaji pemikira para tokoh-tokoh pendidikan di Indonesia.idak lain tujuannaya yaitu bagaiana supaya pendidikan di indoneisa semakin baik.

Berbicara teteng tokoh pendidikan di Indoneseia, banyak sekali yang menjadi panutan pemikirannya, salah satunya yaitu Ki Hajar Dewantara. Di adalah satu dari beribu-ribu tokoh di Indonesia dalam hal pendidikan, Dia adalah bapak pendidikan, selain itu juga mentri pendidikan Indonesia yang pertama sehingga presiden menjadikan hari lahirnya sebaga hari pendidikan.

\section{BIOGRAFI}

Raden Mas Soewardi Soerjaningrat merupakan nama aslinya akan tetapi pada tahun 1922 menjadi KI Hajar Dewantara, Dia dilahirkan di Yogyakarta pada hari Kamis legi tanggal 2 Mei 1889 sebagai putra ke-4 dari pangeran Suryaningrat, putra tertua dari sri paku alam III. Masa kanak-kanak dan remajanya dipengaruhi oleh sastra jawa. Agama Islam dan ajaran-ajaran Hindu Purba. Pahlawan yang dikaguminya dari epik mahabarata adalah yudistira (lambang perdamaian dan cinta) dan Sri Krisna (inkarnasi wishnu yang penuh dengan kebijaksanaanya). ${ }^{4}$

Sejak kecil wataknya ialah independen, non-komfermis dan merakyat. Beliau senang bermain dengan anak-anak orang awam, dan sering tidur bersama mereka di masjid. Beliau juga tidak menyenangi adap artis tokkratis "dhodhoksembah" (jalan berjongkok dan menyembah), dan dengan sengaja melanggar monopoli kraton sultan bahwa kain batik "parang-rusak" itu dilarang dipakai oleh orang awam. ${ }^{5}$

Ki Hajar Dewantara adalah aktivis pergerakan kemerdekaan Indonesia, kolumnis, politisi, dan pelopor pendidikan bagi kaum pribumi Indonesia pada zaman penjajahan belanda. Ia adalah pendiri Perguruan Taman Siswa, suatu lembaga pendidikan yang memberikan kesempatan bagi para pribumi jelata untuk bisa memperoleh hak pendidikan seperti halnya para priyayi maupun orang-orang belanda. ${ }^{6}$

\footnotetext{
${ }^{4}$ Dwi Siswono, Dkk. Ilmu Pendidikan, ( Yogyakarta, UNY Press 2007). HIm.163.

${ }_{6}^{5}$ Ibid, 163

${ }^{6}$ Iwan Setiawan, Tokoh-Tokoh Fenomenal Paling Mempengaruhi Wajah Indonesia, (Jogjakarta, Laksana, 2011). HIm. 133-134.
} 
Tanggal kelahirannya sejarah diperingati sebagai hari pendidikan nasional. Bagian dari semboyan ciptaanya, Tut Wuri Handayani menjadi selogan departemen pendidikan naisonal. Namanya diabadikan sebagai salah satu sama kapal perang Indonesia KRI KI Hajar Dewantara. Potret dirinya diabadikan pada uang kertas 20.000 rupiah. $^{7}$

Jenjang pendidikan KI Hajar Dewantara yaitu menamatkan pendidikan dasar di ELS (sekolah dasar eropa/belanda) kemudian sempat melanjutkan ke STOVIA (sekolah dokter bumiputra), karena dia sakit sehingga dia tidak bisa tamat di Stiopia. Kemudian dia mengawali karirnya sebagai penulis dan wartawan diberbagai surat kabar, seperti sediotomo, midden java, de expres, oetoesan hindia, kaoem moeda, tjabaja timoer, dan poesara. Pada masanya, ia termasuk peulis handal, tulisan-tulisanya komunikatif dengan semangat antikolonial.

Selain aktiv sebagai wartawan, dia jauga aktif menjadi aktivis sejak berdirinya boedi oetomo, taun 1008, ia aktif diseksi propaganda untuk mensosialisaiskan dan menggugah kesadaran masyarakat Indonesia pada waktu itu mengenai pentinya persatuan da kesatuan dalam berbangsa dan bernegara. Kongres pertama BO di Yogyakarta juga diorganisasi olehnya.

Selain aktif di BO, KI Hajar Dewantara juga menjadi anggota Rganisasi Insulinde, suatu organisasi multietnik yang didominasi kaum indo yang memperjuangkan pemerintahan sendiri di hindia belanda atas pengaruh Ernest Douwes Dekker (dd).

Adapun jabatan yang pernah dia duduki yatu sebagai menteri pengajaran pada tahun 1959, selain itu dia juga mendapatkan gelar kehormatan (doctor honoris cause, dr. hc) dari Universitas Gajah Mada atas jasa-jasanya dalam merintis pendidikan umum. Dan dia meninggal di Jogjakarta tanggal 26 April 1959 dan dimakamkan juga di Yogyakarta. ${ }^{8}$

Jiwa Soewardi sangat peka terhadap keadaan lingkungannya, terutama mengenai kehidupan kerabat istana. Keadaan ekonomis yang sangat menyolok, keterbatasan hak yang ada pada rakyat dan berbagai ketimpangan sosial lainya,

\footnotetext{
7 Ibid, 134.

8 Ibid..138.
} 
menimbulkan sikap protes dalam hati Soewardi, yang kemudian terpupuk menjadi dasar sifatnya yang kerakyatan dan revolisioner, dalam perkembangan kepribadianya selanjutnya, Soewardi menjadi seorang yang berjiwa nasional, yang selalu tergelitik hatinya untuk mengandalkan perubahan dalam peri kehidupan bangsanya.

Soewardi yang berjiwa progresif dan agresif bersama-sama dengan dr. Tjipto Mangoenkoesemo dan dr. Douwes Dekker, yang terkenal sebagai "tiga serangkai". Pada tahun 1912 mendirikan Indische Partij (IP) dengan semboyan "rawe-rawe rantas", beraksi untuk Indonesia merdeka dan berdaulat. Pertumbuhan jiwa Soewardi menjadi semakin jelas ketangkasannya di dalam menyerang pihak belanda kolonial.

Aktivitas politiknya dalam Budi Utomo, Sarikat Islam, dan Indische Partij memuncak dalam kritik yang berjudul buku siaran "als ik eens nederlender was" (seandainya aku seorang belanda), yang merupakan reaksi terhadap rencana gubernemen belanda yang akan mengadakan peringatan besar-besaran 100 tahun kemerdekaan negeri belanda di tanah jajahan indonesia pada tanggal 15 Nopember 1913, sesudah dijajah perancis dibawah Napoleon.

Di dalam tulisannya Soewardi memberi tamparan yang hebat kepada si angkara murka penjajah, tetapi caranya tidak kasar, tidak dengan maki-maki, senantiasa tetap sebagai ksatria, memberi kata-kata yang tepat, jitu, indah susunanya, ada humornya, ada sinisya, tercampur ejekan yang pedas, yang dilemparkan kepada si penjajah, tetapi selanjutnya juga memberi pandanganpandangan, dapat direnungkan pihak belanda, dan juga fihak kita. Kesemuanya itu menuju kepengasingannya melalui dekrit gubernur jendral belanda tertanggal 18 Agustus 1913, Soewardi diasingkan ke Bangka, dr. Tjipto Mangoenkoesoema ke Banda Neira, dan dr. Douwes Dekker alias dr. Danu Dirdjo Setiabudhi ke Timur Kupang, namun akhirnya ketiganya diperkenankan untuk pergi kenegeri belanda (1913-1919).

\section{Pemberian Gelar Doctor Honoris Causia}

Rector Universitas Gajah Mada, Prof. Dr. M. Sarjito, selaku promoter dalam pemberian gelar doctor honoris causia dakan "ilmu kebudayaan" kepada KI 
Hajar Dewantara, pada tanggal 19 Desember tahun 1965 di Sitihinggil Yogyakarta, menyatakan KI Hajar Dewantara dipandang sebagai perintis kemerdekaan nasional, perintis pendidikan nasional dan perintis budayaan nasional. Di dalam diri KI Hajar Dewantara, senat Universitas Gajah Mada menganggap menemukan perintis hidup kebudayaan dalam arti luas isinya dan luas lingkungannya, terutama hidup kebudayaan Indonesia dan juga hidup kebudayaan umummnya. ${ }^{9}$

\section{Arti Pendidikan Dalam Pandangan Ki Hajar Dewantara}

Dalam pandangan KI Hajar Dewantara, pendidiikan umumnya berarti daya upaya untuk memajukan bertumbuhnya budi pekerti (kekuatan batin, karakter), pikiran (intellect) dan tubuh anak. ${ }^{10}$ Berdasarkan penjelasan tersebut, pendidikan tidak lain tujuannya yaitu untuk merubah sikap seseorang yang dulunya tidak baik menajdi baik.

Bila dicermati sekarang ini budi pekerti (ahlak) kuarang sekali, banyak kita lihat melalui televisi maupun surat kabar bahwa ahlak sudah sangat merosot sekali, melihat hal seperti itu maka pemerintah memberikan pembelajaran mulai dari tingkat SD untuk diberikan pendidikan ahlak terhadap peserta didik, supaya apa yang menjadi tujuan pendidikan tersebut bisa tercapai.

Selain budi pekerti, menurut KI Hajar Dewantara, pendidikan tujuannya yaitu untuk meningkatkan kecerdasan seseorang atau pengetahuan seseorang. Sebab dengan pendidikan maka seseorang tersebut menjadi lebih pintar dan cerdar. Menurut KI Hajar Dewantara pendiikan dan pengajaran mempunyai arti tersendiri. Pengajara (onderwijs) ialah salah satu bagian dari pendidikan, dimana pendidikan itu ialah pendidikan dengan cara memberi ilmu atau pengetahuan, serta juga memberi kecakapan kepada anak-anak, yang kedua-duanya dapat berfaedah buat hidup anak-anak, baik lahir maupun batin.

Sedangkan arti dan maksud pedidikan dalam arti umum yaitu tuntutan di dalam hidup tubuhnya anak-anak. Adapun maksud pendidikan yaitu menuntun segala kekuatan kodrat yang ada pada anak-anak itu, agar mereka sebagai manusia

\footnotetext{
${ }^{9}$ Dwi Siswono, dkk. Ilmu Pendidikan,( Yogyakarta, UNY Press 2007). HIm.165-166

${ }^{10}$ KI Hajar Dewantara, Majlis Luhur Persatuan Tamansiswa, Yogykarta : 2011, hlm. 14.
} 
dan anggauta masyarakat dapatlah mencapai keselamatan dan kebahagiaan yang setinggi-tingginya. ${ }^{11}$

Sedangkan menurt Arif Rihman, pendiikan secara etimologis atau kebahasaan, kata 'pendidikan' berasal dari kata dasar 'didik' yang mendapat imbuhan awalan dan akhiran pe-an. Berubah menjadi kata kerja 'mendidik' yang berarti membantu anak utuk menguasai aneka pengetahuan, keterampilan, sikap, dan nilai yang diwarisi dari keluarga dan masyarakatnya. ${ }^{12}$

Berdasarkan penjelasan di atas, pendidikan dam pengajaran menurut $\mathrm{Ki}$ Hajar Dewantara mempunyai arti tersendiri,di mana pendidikan tersebut lebih kepada memberikan atau mengajarkan anak akan pengetahuan, sedangkan pengajaran tersebut lebih kepada pemberian contoh atau sikap terhadap anak tersebut. Sedangkan menurut Arif Rohman pendikan yaitu bagaimana seorang guru membantu peseta didik untuk tahu bahasa, sikap dan lain-lain.

\section{Peran KI Hajar Dewantara Dalam Dunia Pendidikan}

\section{Ki Hajar Dewantara Aktif Membangkitkan Semangat Antikolonial Melalui Tulisan-Tulisannya}

Setelah Ki Hajar Dewantara menamatkan Sekolah Dasar di ELS (Sekolah Dasar Belanda) Kemudian sempat melanjut ke STOVIA (Sekolah Dokter Bumiputera), tapi tidak sampai tamat karena sakit. Kemudian ia bekerja sebagai wartawan di beberapa surat kabar antara lain Sedyotomo, Midden Java, De Express, Oetoesan Hindia, Kaoem Moeda, Tjahaja Timoer dan Poesara. Pada masanya, ia tergolong penulis handal. Tulisan-tulisannya sangat komunikatif, tajam dan patriotik sehingga mampu membangkitkan semangat antikolonial bagi pembacanya.

"Tulisan-tulisannya sangat komunikatif, tajam dan patriotik sehingga mampu membangkitkan semangat antikolonial bagi pembacanya"

\footnotetext{
${ }^{11}$ KI Hajar Dewantara, hlm : 20.

12 Arif Rohman, Memahami Ilmu Pendidikan, (Yogyakarta, CV. Aswaja Pressindo, : 2013), hlm. 5.
} 


\section{Aktif Dalam Organisasi Sosial Dan Politik}

Selain ulet sebagai seorang wartawan muda, Ki Hajar Dewantara juga aktif dalam organisasi sosial dan politik. Pada tahun 1908, ia aktif di seksi propaganda Boedi Oetomo untuk mensosialisasikan dan menggugah kesadaran masyarakat Indonesia pada waktu itu mengenai pentingnya persatuan dan kesatuan dalam berbangsa dan bernegara.

"Ki Hajar Dewantara aktif mensosialisasikan dan menggugah kesadaran masyarakat Indonesia mengenai pentingnya persatuan dan kesatuan dalam berbangsa dan bernegara"

\section{Mendirikan Indische Partij Bertujuan Mencapai Indonesia Merdeka}

Bersama Douwes Dekker (Dr. Danudirdja Setyabudhi) dan dr. Cipto Mangoenkoesoemo, Ki Hajar Dewantara mendirikan Indische Partij (partai politik pertama yang beraliran nasionalisme Indonesia) pada tanggal 25 Desember 1912 yang bertujuan mencapai Indonesia merdeka. Mereka berusaha mendaftarkan organisasi ini untuk memperoleh status badan hukum pada pemerintah kolonial Belanda. Tetapi pemerintah kolonial Belanda melalui Gubernur Jendral Idenburg berusaha menghalangi kehadiran partai ini dengan menolak pendaftaran itu pada tanggal 11 Maret 1913. Alasan penolakannya adalah karena organisasi ini dianggap dapat membangkitkan rasa nasionalisme rakyat dan menggerakan kesatuan untuk menentang pemerintah kolonial Belanda.

“Alasan penolakannya adalah karena organisasi ini dianggap dapat membangkitkan rasa nasionalisme rakyat dan menggerakan kesatuan untuk menentang pemerintah kolonial Belanda”

\section{Membentuk Komite Bumipoetra}

Setelah ditolaknya pendaftaran status badan hukum Indische Partij, Ki Hajar Dewantara pun ikut membentuk Komite Bumipoetra pada November 1913. Komite itu sekaligus sebagai komite tandingan dari Komite Perayaan Seratus Tahun Kemerdekaan Bangsa Belanda. Komite Boemipoetra itu melancarkan kritik terhadap Pemerintah Belanda yang bermaksud merayakan seratus tahun bebasnya 
negeri Belanda dari penjajahan Prancis dengan menarik uang dari rakyat jajahannya untuk membiayai pesta perayaan tersebut.

"Komite Boemipoetra itu melancarkan kritik terhadap Pemerintah Belanda yang bermaksud merayakan seratus tahun bebasnya negeri Belanda dari penjajahan Prancis dengan menarik uang dari rakyat jajahannya untuk membiayai pesta perayaan tersebut”

\section{Ki Hajar Dewantara mengkritik lewat tulisan berjudul Als Ik Eens Nederlander Was dan Een voor Allen maar Ook Allen voor Een}

Sehubungan dengan rencana perayaan itu, ia pun mengkritik lewat tulisan berjudul Als Ik Eens Nederlander Was (Seandainya Aku Seorang Belanda) dan Een voor Allen maar Ook Allen voor Een (Satu untuk Semua, tetapi Semua untuk Satu Juga). Tulisan Seandainya Aku Seorang Belanda yang dimuat dalam surat kabar de Expres milik dr. Douwes Dekker itu antara lain berbunyi:

"Sekiranya aku seorang Belanda, aku tidak akan menyelenggarakan pesta-pesta kemerdekaan di negeri yang kita sendiri telah merampas kemerdekaannya. Sejajar dengan jalan pikiran itu, bukan saja tidak adil, tetapi juga tidak pantas untuk menyuruh si inlander memberikan sumbangan untuk dana perayaan itu."

"Pikiran untuk menyelenggarakan perayaan itu saja sudah menghina mereka dan sekarang kita garuk pula kantongnya. Ayo teruskan penghinaan lahir dan batin itu! Kalau aku seorang Belanda. Apa yang menyinggung perasaanku dan kawan-kawan sebangsaku terutama ialah kenyataan bahwa bangsa inlander diharuskan ikut mengongkosi suatu pekerjaan yang ia sendiri tidak ada kepentingannya sedikitpun”.

Akibat karangannya itu, pemerintah kolonial Belanda melalui Gubernur Jendral Idenburg menjatuhkan hukuman tanpa proses pengadilan, berupa hukuman internering (hukum buang) yaitu sebuah hukuman dengan menunjuk sebuah tempat tinggal yang boleh bagi seseorang untuk bertempat tinggal. Ia pun dihukum buang ke Pulau Bangka. 
Douwes Dekker dan Cipto Mangoenkoesoemo merasakan rekan seperjuangan diperlakukan tidak adil. Mereka pun menerbitkan tulisan yang bernada membela Soewardi. Tetapi pihak Belanda menganggap tulisan itu menghasut rakyat untuk memusuhi dan memberontak pada pemerinah kolonial. Akibatnya keduanya juga terkena hukuman internering. Douwes Dekker dibuang di Kupang dan Cipto Mangoenkoesoemo dibuang ke pulau Banda. Namun mereka menghendaki dibuang ke Negeri Belanda karena di sana mereka bisa memperlajari banyak hal dari pada didaerah terpencil. Akhirnya mereka diijinkan ke Negeri Belanda sejak Agustus 1913 sebagai bagian dari pelaksanaan hukuman.

Kesempatan itu dipergunakan untuk mendalami masalah pendidikan dan pengajaran, sehingga Raden Mas Soewardi Soeryaningrat berhasil memperoleh Europeesche Akte. Kemudian ia kembali ke tanah air di tahun 1918. Di tanah air ia mencurahkan perhatian di bidang pendidikan sebagai bagian dari alat perjuangan meraih kemerdekaan.

\section{Mendirikan Sebuah Perguruan yang Bercorak Nasional (Tamansiswa)}

Setelah pulang dari pengasingan, bersama rekan-rekan seperjuangannya, ia pun mendirikan sebuah perguruan yang bercorak nasional, Nationaal Onderwijs Instituut Tamansiswa (Perguruan Nasional Tamansiswa) pada 3 Juli 1922. Perguruan ini sangat menekankan pendidikan rasa kebangsaan kepada peserta didik agar mereka mencintai bangsa dan tanah air dan berjuang untuk memperoleh kemerdekaan.

"Ia pun mendirikan sebuah perguruan yang bercorak nasional, Nationaal Onderwijs Instituut Tamansiswa (Perguruan Nasional Tamansiswa) pada 3 Juli 1922”

\section{Ki Hajar Dewantara Gigih Memperjuangkan Hak}

Tidak sedikit rintangan yang dihadapi dalam membina Taman Siswa. Pemerintah kolonial Belanda berupaya merintanginya dengan mengeluarkan Ordonansi Sekolah Liar pada 1 Oktober 1932. Tetapi dengan kegigihan memperjuangkan haknya, sehingga ordonansi itu kemudian dicabut. 
"dengan kegigihan memperjuangkan haknya, sehingga ordonansi sekolah liar yang dikeluarkan oleh kolonial Belanda akhirnya dicabut”,

\section{Membuat Tulisan Yang Meletakkan Dasar-Dasar Pendidikan Nasional Bagi Bangsa Indonesia}

Di tengah keseriusannya mencurahkan perhatian dalam dunia pendidikan di Tamansiswa, ia juga tetap rajin menulis. Namun tema tulisannya beralih dari nuansa politik ke pendidikan dan kebudayaan berwawasan kebangsaan. Tulisannya berjumlah ratusan buah. Melalui tulisan-tulisan itulah dia berhasil meletakkan dasar-dasar pendidikan nasional bagi bangsa Indonesia.

"Ki Hajar Dewantara rajin membuat tulisan-tulisan tentang dasardasar pendidikan nasional bagi bangsa Indonesia”

\section{Membentuk Pusat Tenaga Rakyat (Putera) Pada Pemerintahan Jepang}

Sementara itu, pada zaman Pendudukan Jepang, kegiatan di bidang politik dan pendidikan tetap dilanjutkan. Waktu Pemerintah Jepang membentuk Pusat Tenaga Rakyat (Putera) dalam tahun 1943, Ki Hajar duduk sebagai salah seorang pimpinan di samping Ir. Soekarno, Drs. Muhammad Hatta dan K.H. Mas Mansur.

“Waktu Pemerintah Jepang membentuk Pusat Tenaga Rakyat (Putera) dalam tahun 1943, Ki Hajar duduk sebagai salah seorang pimpinan di samping Ir. Soekarno, Drs. Muhammad Hatta dan K.H. Mas Mansur”

\section{Ki Hajar Dewantara Menjabat Sebagai Menteri Pendidikan, Pengajaran Dan Kebudayaan Yang Pertama.}

Setelah zaman kemedekaan, Ki hajar Dewantara pernah menjabat sebagai Menteri Pendidikan, Pengajaran dan Kebudayaan yang pertama. Nama Ki Hadjar Dewantara bukan saja diabadikan sebagai seorang tokoh dan pahlawan pendidikan (bapak Pendidikan Nasional) yang tanggal kelahirannya 2 Mei dijadikan hari Pendidikan Nasional, tetapi juga ditetapkan sebagai Pahlawan Pergerakan Nasional melalui surat keputusan Presiden RI No.305 Tahun 1959, tanggal 28 November 
1959. Penghargaan lain yang diterimanya adalah gelar Doctor Honoris Causa dari Universitas Gajah Mada pada tahun 1957.

"Nama Ki Hadjar Dewantara diabadikan sebagai seorang tokoh dan pahlawan pendidikan (bapak Pendidikan Nasional) yang tanggal kelahirannya 2 Mei dijadikan hari Pendidikan Nasional, dan ditetapkan sebagai Pahlawan Pergerakan Nasional melalui surat keputusan Presiden RI No.305 Tahun 1959, tanggal 28 November $1959^{\prime \prime}$

\section{Ki Hajar Dewantara Melahirkan Pemikiran Tentang Tujuan Pendidikan}

Bangsa ini perlu mewarisi buah pemikirannya tentang tujuan pendidikan yaitu memajukan bangsa secara keseluruhan tanpa membeda-bedakan agama, etnis, suku, budaya, adat, kebiasaan, status ekonomi, status sosial, dan sebagainya, serta harus didasarkan kepada nilai-nilai kemerdekaan yang asasi.

"Pemikirannya tentang tujuan pendidikan yaitu memajukan bangsa secara keseluruhan tanpa membeda-bedakan agama, etnis, suku, budaya, adat, kebiasaan, status ekonomi, status sosial, dan sebagainya, serta harus didasarkan kepada nilai-nilai kemerdekaan yang asasi”

\section{Melahirkan Ajaran Tut Wuri Handayani}

Ki Hajar Dewantara juga melahirkan ajarannya yang terkenal yaitu tut wuri handayani (di belakang memberi dorongan), ing madya mangun karsa (di tengah menciptakan peluang untuk berprakarsa), ing ngarsa sungtulada (di depan memberi teladan).

"Tut wuri handayani (di belakang memberi dorongan), ing madya mangun karsa (di tengah menciptakan peluang untuk berprakarsa), ing ngarsa sungtulada (di depan memberi teladan)" 


\section{Ki Hajar Dewantara Mendirikan Perguruan Dengan Berciri Pancadarma}

Ki Hajar Dewantara mendirikan Perguruan Tamansiswa pada tahun 1922, dimana pendidikan Tamansiswa berciri khas Pancadarma, yaitu 1) Kodrat Alam; 2) Kemerdekaan; 3) Kebudayaan; 4) Kebangsaan; 5) Kemanusian, yang berdasarkan Pancasila.

"Tamansiswa berciri khas Pancadarma, yaitu 1) Kodrat Alam; 2) Kemerdekaan; 3) Kebudayaan; 4) Kebangsaan; 5) Kemanusian, yang berdasarkan Pancasila"

\section{Ki Hajar Dewantara Aktif Membuat Karya Tulis Dan Risalah Penting, Dan Surat-Surat Mengenai Pendidikan}

Beliau aktif menulis karya tulis atau konsep dan risalah-risalah penting serta data surat-menyurat tentang pendidikan demi memajukan pendidikan bangsa Indonesia.

\section{Teori Trikon Ki Hajar Dewantara}

Upaya kebudayaan (pendidikan) menurut $\mathrm{Ki}$ Hajar Dewantara dapat ditempuh dengan sikap (laku) yang dikenal dengan teori Trikon, yaitu: Pertama, Kontinuitas yang berarti bahwa garis hidup kita sekarang harus merupakan lanjutan dari kehidupan kita pada zaman lampau berikut penguasaan unsur tiruan dari kehidupan dan kebudayaan bangsa lain. Kedua, Konvergensi, yaitu berarti kita harus menghindari hidup menyendiri, terisolasi dan mampu menuju kearah pertemuan antar bangsa dan komunikasi antar negara menuju kemakmuran bersama atas dasar saling menghormati, persamaam hak, dan kemerdekaan masingmasing. Ketiga, Konsentris, yang berarti setelah kita bersatu dan berkomunukasi dengan bangsa-bangsa lain di dunia, kita jangan kehilangan kepribadian sendiri. Bangsa Indonesia adalah masyarakat merdeka yang memiliki adat istiadat dan kepribadian sendiri. 


\title{
Tri Sentra Pendidikan Ki Hajar Dewantara
}

Pelaksanaan pendidikan menurut Ki Hajar Dewantara dapat berlangsung dalam berbagai tempat yang oleh beliau diberinama Tri Sentra Pendidikan, yakni (a) Alam keluarga. (b) Alam Perguruan. Dan (c) Alam Pergergerakan pemuda.

\section{Ki Hajar Dewantara Mewariskan Ajaran-Ajaran Karakter Dan Budaya}

Ajaran-ajaran yang diwariskan oleh Ki Hajar Dewantara yaitu Trihayu, Trilogi Kepemimpinan, dan Tripantang.

\begin{abstract}
"Konsep Trihayu" yang terdiri dari mamayu hayuning sarira, mamayu hayuning bangsa, dan mamayu hayuning bawana. Maksudnya, apapun yang diperbuat oleh seseorang itu hendaknya dapat bermanfaat bagi dirinya sendiri, bermanfaat bagi bangsa, dan bermanfaat bagi manusia di dunia pada umumnya". ${ }^{13}$
\end{abstract}

Melihat dari cuprikan di atas, begitu banyak peran dan sumbangsih peikiran ki hajar dewantara terhadap penididkan di Indonesia, bila di cermati muai dari Indonesia belum merdeka, dia sudah menyumbangkan banyak pemikirannya, mulai dari membangun partai yang berlandaskan nasional, selain itu membangu sekolah rakyat atau taman siswa, sebab pada masa itu sekolah di Indonesia belum berlnadsaskan nasional, sehingga dia berinisiatip untuk membangun sebuh sekolah yaitu tamn siswa yang sampai sekarang semakin maju bahkan sudah menajdi sebuah uiversitas di Jogjakarta dan sudah mempunyai banya cabang di Indonesia.

Selin itu juga KI Hajar Dewantara merumuskan sebuah teori dan seloganselogan pendidikan, bahkan sampai saat ini selogan-selogan KI Hajar Dewantara masih berlaku dan di tuis di depan sekolah sebagai lambing, seperti tut wuri handayai yang sampai saat ini masih berlaku dan di abadikan di topi siswa-siswa sekolah dasar. Itu menunjukkan bahwa pemikiran ki haajr dewantara dalam dunia pendidikan sampai saat ini masih relefan dengan dunia sekarang.

13 http://ayosebarkan.com/17-jasa-ki-hajar-dewantara-untuk-pendidikan-diindonesia/. Di akses senin 15 Januari 2018, waktu 14:18 wit. 


\section{KESIMPULAN}

Pendidikan pada dasarnya adalah usaha sadar untuk menumbuhkembangkan potensi sumber daya manusia peserta didik dengan cara mendorong dan memfasilitasi kegiatan belajar mereka, Seperti tercantum dalam undang-undang. ${ }^{14}$ Menfasilitasi kegiatan belajar seperti alat-alat bantu kegiatan belajar seperti laboraturium sekolah, buku, ruangan kelas, dan lain-lain yang terkait dengan kebutuhan siswa dan guru dalam proses pembelajaran.

Raden Mas Soewardi Soerjaningrat merupakan nama aslinya akan tetapi pada tahun 1922 menjadi KI Hajar Dewantara, Dia dilahirkan di Yogyakarta pada hari Kamis legi tanggal 2 Mei 1889 sebagai putra ke-4 dari pangeran Suryaningrat, putra tertua dari sri paku alam III. Masa kanak-kanak dan remajanya dipengaruhi oleh sastra jawa. Agama Islam dan ajaran-ajaran Hindu Purba. Pahlawan yang dikaguminya dari epik mahabarata adalah yudistira (lambang perdamaian dan cinta) dan Sri Krisna (inkarnasi wishnu yang penuh dengan kebijaksanaanya).

Adapun jabatan yang pernah dia duduki yatu sebagai menteri pengajaran pada tahun 1959, selain itu dia juga mendapatkan gelar kehormatan (doctor honoris cause, dr. hc) dari Universitas Gajah Mada atas jasa-jasanya dalam merintis pendidikan umum. Dan dia meninggal di Jogjakarta tanggal 26 April 1959 dan dimakamkan juga di Yogyakarta.

\section{Daftar Pustaka}

Dedi Mulyasa, Pendidikan Bermutu, Bandung : PT Remaja Rosdakarya, 2012.

Suyono dan Hariyanto, Belajar Dan Pembelajaran, Bandung : PT Remaja Rosdakarya Offset, 2012.

Muhibbbin Syah, Psikologi Pendidikan. Jakarta : PT. Raja Grapindo Persada. 2009.

Dwi Siswono, dkk. Ilmu Pendidikan, Yogyakarta, UNY Press, 2007.

Iwan Setiawan, Tokoh-Tokoh Fenomenal Paing Mempengaruhi Wajah Indonesia, Jogjakarta : Laksana, 2011.

http://ayo sebarkan.com/17-jasa-ki-hajar-dewantara-untuk-pend idikan-diindonesia/.

Di akses senin 15 Januari 2018 , waktu 14:18 WIB.

Ki Hajar Dewantara, Majlis Luhur Persatuan Tamansiswa, Yogykarta : 2011

${ }^{14}$ Muhibbbin Syah, Psikologi Pendidikan. (Jakarta : PT. Rajagrapindo Persada. 2009). HIm.1 
Arif Rohman, Memahami Ilmu Pendidikan, CV. Aswaja 